\section{Systolic Time Intervals in Type 1 (Insulin-Dependent) Diabetes Mellitus During Exercise}

Dear Sir,

In a recent publication, Posner and colleagues [1] were unable to find any signs of subclinical cardiomyopathy as detected by measurements of systolic time intervals (STI) at rest in Type 1 (insulin-dependent) and Type 2 (non-insulin-dependent) diabetic patients. This is in contrast to reports from other authors [2-4]. Posner et al. suggested that testing of systolic performance after exercise might be more informative.

To evaluate the usefulness of STI for detecting the preclinical cardiac disorders in diabetic patients, we have studied the effect of volume-loading, isometric handgrip test and dynamic exercise on STI in diabetic subjects. Thirty-two patients with Type 1 diabetes were selected from our medical departments; their age ranged from 16 to 43 years (mean 30 years) with duration of diabetes mellitus from 1 to 28 years (mean 11.3 years). Clinical signs of diabetic microangiopathy were present in 12 patients. None had any clinical, electrocardiographic or X-ray evidence of heart or lung diseases, and arterial blood pressures were within the normal range. All patients were on conventional insulin treatment, without any clinical or laboratory signs of Ketoacidosis. Patients with ethanol abuse, those receiving drugs which might affect cardiac performance, smokers of more than 20 cigarettes daily and the obese (more than 15\% above ideal body weight) were excluded. Twenty-nine age and sex-matched healthy individuals served as controls.

During volume loading, isometric handgrip and dynamic exercise tests performed in random order on 3 consecutive days, STI were measured in the supine position after determination of resting values. Volume loading was induced by passive leg raising for $1 \mathrm{~min}$. Isometric handgrip test [5] was performed at $50 \%$ of maximal voluntary capacity for $3 \mathrm{~min}$. Dynamic exercise was carried out up to two-thirds of the calculated maximum heart rate for each individual. Instead of the widely used regression equation of Weisler et al. [6], the values of preejection period (PEP) and those of left ventricular ejection time (LVET) were corrected $\left(\mathrm{PEP}_{\mathrm{s}}, \mathrm{LVET}_{\mathrm{c}}\right.$ ) to the resting heart rate of each individual, using a regression equation established in our laboratory.

Comparing the diabetic and control groups, the mean values of resting heart rate as well as mean values of resting arterial blood pressure did not differ significantly, while during the tests these parameters increased significantly in each group (data not shown). The resting values of STI and changes during the tests are presented in Table 1. Higher values of $\mathrm{PEP}_{\mathrm{c}}$ leading to an increased $\mathrm{PEP} / \mathrm{LVET}$ ra- tio could be demonstrated in diabetic patients at rest. PEP/LVET ratios were significantly decreased in healthy subjects during all three tests. In the diabetic patients the PEP/LVET ratios remained unchanged during volume loading and handgrip tests, while they decreased during dynamic exercise test compared with their resting values. These decreases of PEP/LVET ratios, however, differed significantly from the similar values observed in controls, and were the consequence of changes both in $\mathrm{PEP}_{\mathrm{c}}$ and $\mathrm{LVET}_{\mathrm{c}}$.

In conclusion, testing of STI during exercise might be useful in the detection of left ventricular dysfunction in diabetic subjects and abnormalities thus detected might be a preclinical sign of diabetic cardiomyopathy.

Yours sincerely,

Gy. Jermendy, L. Kammerer, Zs. M. Koltai, L. Cserhalmi and G. Pogatsa

\section{References}

1. Posner J, Ilya R, Wanderman K, Weitzman S (1983) Systolic time intervals in diabetes. Diabetologia 24: $249-252$

2. Ahmed SS, Jaferi GA, Narang RM, Regan TJ (1975) Preclinical abnormality of left ventricular function in diabetes mellitus. Am Heart J 89: 153-158

3. Seneviratne BIB (1977) Diabetic cardiomyopathy: the preclinical phase. Br Med J 1: 1444-1446

4. Zoneraich S, Zoneraich O, Rhee JJ (1977) Left ventricular performance in diabetic patients without clinical heart disease. Chest 72 : $748-751$

5. Kivowitz C, Parmley WW, Donoso R, Marcus H, Ganz W, Swan HJC (1971) Effects of isometric exercise on cardiac performance. The grip test. Circulation 44: 994-1002

6. Weissler AM, Harris WS, Schoenfeld CD (1968) Systolic time intervals in heart failure in man. Circulation 37: 149-159

Dr. G. Pogátsa

National Institute of Cardiology

Budapest, Hungary

H-1450 P.O. B. $9-88$

Table 1. Systolic time intervals in diabetic and healthy subjects

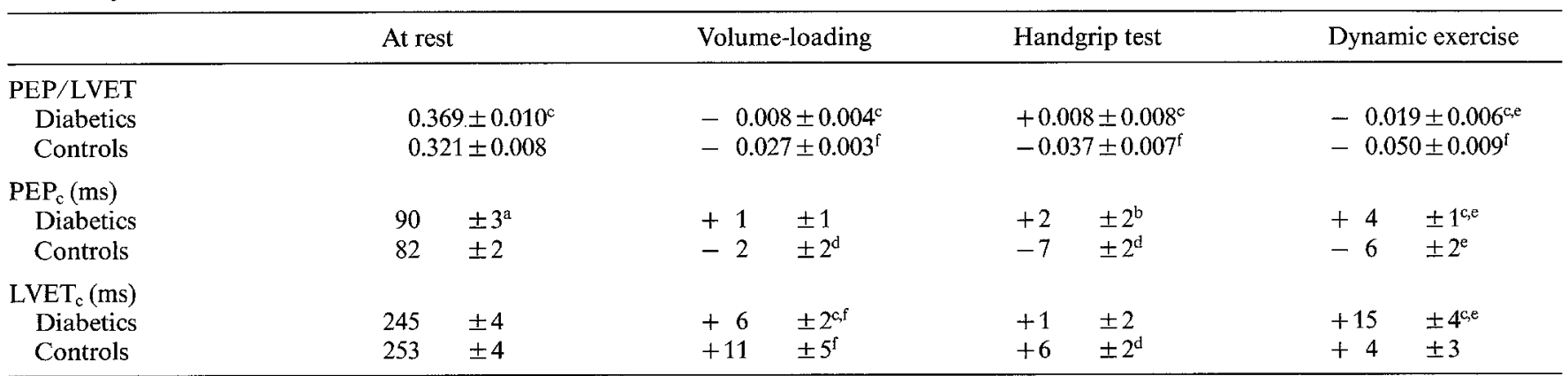

Results expressed as mean \pm SEM. Differences between diabetic and control groups: ${ }^{\mathrm{a}} p<0.05,{ }^{\mathrm{b}} p<0.01,{ }^{\mathrm{c}} p<0.001$; differences compared with resting value: ${ }^{\mathrm{d}} p<0.05,{ }^{\mathrm{e}} p<0.01,{ }^{\mathrm{f}} p<0.001$ 